\title{
KOMUNIKASI PEMASARAN TERPADU SEBAGAI STRATEGI PROMOSI USAHA MIKRO KECIL MENENGAH (UMKM) KERAJINAN ATAP RUMBIA UNTUK MENINGKATKAN PEREKONOMIAN MASYARAKAT KELURAHAN KALAWA KABUPATEN PULANG PISAU
}

\author{
Muhammad Andi ${ }^{1}$, Bekti Ferdasari ${ }^{2}$, Adeputri Wulandari ${ }^{3}$, Rahmadi Syahputra $^{4}$ \\ ${ }^{1}$ FKIP Universitas Palangka Raya \\ ${ }^{2}$ FKIP Universitas Palangka Raya \\ ${ }^{3}$ FKIP Universitas Palangka Raya \\ ${ }^{4}$ Fakultas Pertanian Universitas Palangka Raya
}

muhammadhamkaandiawaliyah@gmail.com, bektiferdasari@gmail.com, depualways@gmail.com, rahmadisyahputra19@gmail.com

\begin{abstract}
Abstrak
Salah satu tanaman yang banyak dijumpai di Kelurahan Kalawa adalah tanaman rumbia. Sifat daunnya yang keras dan kuat sehingga dimanfaatkan warga sekitar sebagai kerajinan khas daerah tersebut yang dikenal dengan kerajinan atap rumbia. Hasil observasi menunjukkan bahwa pengrajin kesulitan dalam proses pemasaran akibat kurang dikenal oleh masyarakat secara luas. Pengabdian kepada masyarakat yang dilakukan oleh kelompok 62 KKN-T Universitas Palangka Raya dilaksanakan pada 7 Agustus - 7 September 2021 di Kelurahan Kalawa Kabupaten Pulang Pisau, Kalimantan Tengah. Kegiatan ini bertujuan untuk membantu promosi UMKM atap rumbia. Metode yang digunakan adalah pelatihan promosi atau penjualan produk melalui sosial media, pembuatan spanduk/benner untuk pelaku UMKM dan pemanfaatan website Kelurahan Kalawa. Hasil dari kegiatan ini adalah pelaku UMKM mampu memanfaatkan sosial media untuk keperluan promosi dan pemasaran, adanya benner sebagai penanda keberadaan UMKM serta pemaksimalan website Kelurahan Kalawa untuk keperluan promosi produk berbasis kearifan lokal. Kegiatan ini diharapkan mampu memperkenalkan produk kerajinan atap rumbia serta meningkatkan perekonomian masyarakat secara umum dan secara khusus bagi pengrajin UMKM.
\end{abstract}

Kata Kunci : promosi, atap rumbia, UMKM

\section{PENDAHULUAN}

Kelurahan Kalawa yang terletak di Kabupaten Pulang Pisau merupakan kawasan dengan kondisi tanah gambut dan berawa. Kondisi tanah gambut dan berawa memberikan pengaruh terhadap jenis tanaman yang cocok pada kondisi tersebut. Salah satu tanaman yang cocok dan umunya dijumpai pada Kelurahan kalawa adalah tanaman rumbia.
Rumbia merupakan merupakan tanaman yang cocok dan mampu bertahan pada kondisi tanah gambut dan berawa. Rumbia atau yang dikenal dengan Sagu (Metroxylon sagu Rottb.) mempunyai tampilan batang yang cukup besar dan mengandung pati. Secara morfologi, tampilan daun rumbia berbentuk menyirip seperti telapak tangan, serta pinggir daun tajam dan membalik kedalam. Daun-daun berwarna hijau dan

Ekonomi, Sosial, dan Budaya | 1262 
sifatnya yang sangat keras dan kuat (Rahayu, Fitmawati, \& Herman, 2013).

Sifatnya yang keras dan jumlahnya relative banyak, maka masyarakat memanfaatkan daun tersebut sebagai sebuah kerajinan atap rumbia. Kerajinan atap rumbia ini merupakan sebuah kegiatan UMKM yang digeluti sebagian masyarakat Kelurahan Kalawa. Kerajinan ini sifatnya unik, dikarenakan memanfaatkan sesuatu yang menjadi khas daerah tersebut dan jika dikembangkan secara serius, dapat menjadi sebuah sentral UMKM atap rumbia di Kabupaten Pulang Pisau yang akan berdampak positif pada perekonomian masyarakat sekitar. Faktanya, kegiatan UMKM atap rumbia ini mengalami suatu kendala yaitu kurangnya konsumen, padahal jika ditinjau secara kualitas hasil kerajinan atap rumbia yang dihasilkan sangatlah bagus yaitu kuat, bahan yang dipilihpun merupakan bahan-bahan pilihan yang terbaik, serta dianyam dengan teknik tertentu.

Investigasi lapangan menunjukan bahwa UMKM atap rumbia yang ada di Kelurahan Kalawa ini tidak begitu banyak konsumen, hal ini dikarenakan kurang dikenali oleh masyarakat secara luas. Lemahnya promosi yang dilakukan baik itu promosi yang dilakukan oleh para pengrajin ataupun promosi dari pihak kelurahan untuk memperkenalkan UMKM atap rumbia ini ke luar daerah menjadi salah satu faktor penyebab kurang dikenalnya kerajinan ini. Kondisi ini sangatlah disayangkan padahal jika kita meninjau bahwa UMKM memegang peranan penting dari persfektif ekonomi, kesempatan bekerja dan sumber pendapatan, distribusi pendapatan dan pengurangan kemiskinan, serta membangun ekonomi pedesaan (Chrismardani, 2014).

Salah satu cara yang dapat dilakukan untuk memperkenalkan UMKM atap rumbia ini adalah dengan melakukan promosi atau komunikasi pemasaran. Pemasaran di era informasi seperti saat ini adalah komunikasi dan komunikasi adalah pemasaran, sehingga keduanya merupakan dua hal yang tidak dapat dipisahkan (Hidayat, Utami, \& Romodhani, 2011).

Komunikasi pemasaran merupakan sarana yang dapat digunakan sebagai upaya untuk menginformasikan, membujuk, meningkatkan konsumen baik secara langsung ataupun tidak langsung tentang produk yang dijual. Sarana yang digunakan dapat berupa brosur, spanduk (banner), leaflet, dan lainnya yang intinya memuat pesan tentang produk yang dijual (Kotler \& Amstrong, 2004).

Ekonomi, Sosial, dan Budaya | 1263 
Adanya komunikasi pemasaran merupakan suatu solusi untuk memperkenalkan kerajinan atap rumbia di Kelurahan Kalawa. Dengan dilakukannya komunikasi pemasaran maka akan berdampak pada dikenalnya UMKM atap rumbia ini sehingga dapat memberikan peluang untuk meningkatnya perekonomian masyarakat Kelurahan Kalawa.

\section{METODE, ALAT DAN BAHAN}

\section{Analisis Kebutuhan}

Berdasarkan hasil observasi lapangan perlu dilakukannya kegiatan komunikasi pemasaran yaitu promosi UMKM atap rumbia. Kegiatan promosi ini perlu dilakukan oleh pelaku UMKM itu sendiri serta bantuan dari pihak Kelurahan Kalawa. Hasil analisis sesuai dengan kondisi yang ada, kegiatan promosi UMKM dapat dilakukan melalui pembuatan spanduk (benner), penggunaan sosial media seperti facebook, serta pembuatan website. Penggunaan flatform ini sebagai media komunikasi pemasaran dengan pertimbangan sebagai berikut.

a. Pembuatan spanduk (benner) dimaksudkan untuk memberikan informasi kepada masyarakat luar daerah yang bepergian dan melewati jalan lintas Bahaur di Kelurahan Kalawa. b. Penggunaan sosial media dalam hal ini adalah facebook dan lainnya dimaksudkan untuk memberi jangkauan secara luar agar masyarakat mengetahui kerajinan ini. Pertimbangan lainnya adalah masyarakat Kelurahan Kalawa cukup aktif dalam menggunakan sosial media facebook.

c. Pembuatan website dimaksudkan untuk memberikan informasi terkait dengan kondisi Kelurahan Kalawa, dan dapat dimanfaatkan sekaligus untuk mempromosikan jenis UMKM yang ada yaitu kerajinan atap rumbia.

\section{Realisasi Kegiatan}

Tahap observasi UMKM di Kelurahan Kalawa dilaksanakan tanggal 10 Agustus 2020. Selanjutnya adalah tahap realisasi kegiatan yaitu pembuatan spanduk promosi yaitu dilaksanakan tanggal 17 Agustus 2020. Pembuatan web dilaksanakan tanggal 30 agustus 2020 dan serta sosialisasi penggunaan platform sosial media tanggal 30 Agustus 2020. Selanjutnya promosi melalui sosial media seperti facebook dilakukan secara mandiri dan berkelanjutan oleh pelaku UMKM atap rumbia.

\section{Khalayak Sasaran}

Sasaran dalam kegiatan ini adalah: 1) produsen atau pelaku kegiatan UMKM, 2) 
masyarakat secara luas, yaitu seluruh lapisan masyarakat yang menjadi subjek baik itu sebagai konsumen ataupun sebagai sumber informasi untuk konsumen lainnya.

\section{Kerangka Berfikir}

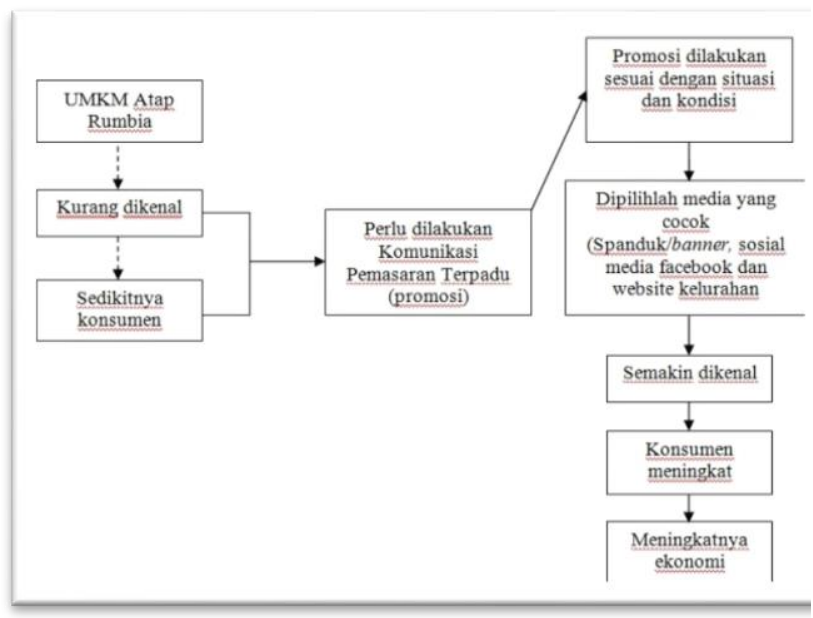

Gambar 1. Kerangka Berpikir

\section{Alat dan Bahan}

Adapun alat dan bahan yang digunakan dalam kegiatan ini adalah sebagai berikut.

Tabel 1. Alat dan bahan

\begin{tabular}{|l|l|}
\hline $\begin{array}{l}\text { Komunikasi } \\
\text { Pemasaran }\end{array}$ & Alat dan Bahan \\
\hline $\begin{array}{l}\text { Pembuatan dan } \\
\text { pemasangan } \\
\text { spanduk/benner }\end{array}$ & $\begin{array}{l}\text { paku, palu, kayu, } \\
\text { gregaji, spanduk dan } \\
\text { tali }\end{array}$ \\
\hline Sosial Media & Facebook \\
\hline $\begin{array}{l}\text { Website Kelurahan } \\
\text { Kalawa }\end{array}$ & komputer/laptop \\
\hline
\end{tabular}

\section{HASIL DAN PEMBAHASAN}

Komunikasi pemasaran atau yang dikenal dengan promosi merupakan salah satu cara yang digunakan untuk proses memperkenalkan produk yang hendak dijual kepada konsumen. Pembuatan rancangan promosi merupakan usaha yang dilakukan oleh lembaga atau instansi ataupun individu untuk memperkenalkan, menghimbau dan memberitahu kepada masyarakat umum. Suatu rancangan promosi harus dirancang sebagus dan semenarik mungkin sehingga masyarakat dapat tertarik dengan informasi yang kita sampaikan terlebih lagi sampai berniat untuk membeli (Putri \& Marlini, 2013).

\section{Penggunaan strategi komunikasi} pemasaran ini bertujuan untuk memperkenalkan secara luas kerajinan atap rumbia yang ada di Kelurahan Kalawa. Dikenalnya Kerajinan ini dapat memberikan peluang untuk meningkatkan jumlah konsumen. Penggunaan strategi kemunikasi pemasaran ini dilakukan dengan promosi menggunakan beberapa media, yaitu menggunakan spanduk sebagai media promosi, penggunaan promosi menggunakan sosial media dalam hal ini adalah facebook dan penggunaan website kelurahan sebagai salah satu media promosi untuk UMKM khas Kelurahan Kalawa. 
Beberapa cara yang dilakukan untuk promosi UMKM atap rumbia adalah sebagai berikut.

\section{Pembuatan dan Pemasangan Spanduk}

Menurut Sulaiman dalam Irmansyah (2018) spanduk merupakan kain rentang yang isinya propaganda ataupun berita/informasi yang perlu diketahui oleh masyarakat umum. Spanduk merupakan sebuah media promosi yang cukup popular, karena harganya yang relative terjangkau dan pengerjaannya yang relative cepat. Fakta lapangan menunjukan bahwa terdapat banyak perusahaan yang memilih spanduk sebagai salah satu media promosi dan tidak jarang perusahaan yang bergerak di bidang periklanan memiliki mesin digital printing sendiri untuk membuat spanduk (Fitriani, 2011).

Pemilihan spanduk sebagai salah satu media yang digunakan untuk promosi UMKM atap rumbia di Kelurahan Kalawa ini mempunyai berbagai macam pertimbangan diantaranya adalah kondisi Kelurahan Kalawa yang dilalui oleh jalan lintas Bahaur yang merupakan jalan penghubung atau jalan lintas dengan daerah lain di Kabupaten Pulang Pisau sehingga menjadi jalan yang seringkali dilalui oleh orang-orang dengan berbagai kepentingan.
Kondisi yang strategis ini dapat memberikan peluang suatu subjek melihat spanduk promosi UMKM atap rumbia yang dipasang di pinggiran jalan akan mendapatkan informasi terkait dengan UMKM atap rumbia yang ada. Dengan satu orang melihat spanduk tersebut akan memberikan peluang tersebarnya informasi ke subjek berikutnya. Sehingga informasi tersebut dapat tersampaikan kepada subjek yang memerlukan.

Selain fungsinya yang dapat mempengaruhi pembaca, menimbulkan kepercayaan, mengingatkan dan menimbulkan loyalitas masyarakat, penggunaan spanduk sebagai media promosi memiliki kelebihan sebagai berikut.

- Proses pembuatan yang tidak telalu rumit.

- Mencakup semua target.

- Penempatannya fleksibel.

- Mudah diingat sebelum membeli produk.

- Dapat dilihat secara berulang-ulang oleh pengguna jalan.

Namun dalam promosi penggunaan spanduk harus memperhatikan beberapa aspek diantaranya desain spanduk yang tidak terlalu berlebihan, pemilihan kalimat yang ringkas lugas dan mudah diingat, ukuran spanduk yang sesuai, tulisan spanduk

Ekonomi, Sosial, dan Budaya | 1266 
yang harus disesuaikan serta penempatan spanduk yang tepat sasaran (Adnani, 2011). Guna mengantisipasi hal ini, kami bekerja sama dengan beberapa pihak yang cukup ahli di bidang desain dan iklan di Kota Palangka Raya untuk mengkonsultasikan pemilihan desain yang tepat dan kalimat yang sangat menarik untuk konsumen.

\section{Penggunaan Sosial Media Facebook}

Berkembangnya teknologi dan informasi menyajikan berbagai media alternative yang digunakan untuk sebuah promosi seperti facebook (Ebeid, 2014). Semakin intensif dilakukannya sebuah promosi pada sosial media akan mendukung dalam meningkatnya brand awareness dari sebuah produk (Schivinski \& Dabrowski, 2015). Promosi tidak hanya berpengaruh pada brand awareness akan tetapi juga dapat mempengaruhi minat beli (Akhter, Rizwan, Shujaat, \& Durrani, 2014). Promosi yang dilakukan melalui sosial media facebook dapat mempengaruhi minat beli konsumen (Duffett, 2015).

Pemilihan sosial media facebook sebagai suatu media promosi untuk UMKM atap rumbia ini dilakukan dengan pertimbangan bahwa masyarakat secara umum setidaknya mempunyai sebuah account facebook dibandingkan sosial media yang lain seperti intagram ataupun twitter. Dengan kata lain jangkauan facebook sangatlah luas. Penggunan sosial media facebook sebagai media promosi tergolong sangatlah mudah yaitu dengan mengupload foto terkait dan jenis usaha serta dibubuhi dengan caption yang menarik. Hanya saja tantangan dalam kegiatan promosi di facebook adalah bergantung pada jaungkauan pertemanan yang dimiliki oleh pelaku promosi sehingga akan sulit terpublikasi secara luas jika tidak menggunakan trick khusus dalam penguploadannya. Selain ditinjau dari jangkauan pertemanan, waktu penguploadan pun perlu diperhatikan agar tidak menimbulkan suatu kegiatan di sosial media yang dinamakan dengan spam.

\section{Penggunaan Website Kelurahan Kalawa}

Saat ini banyak teknologi yang digunakan sebagai sarana promosi dan informasi tanpa terkecuali website. Website mampu memberikan informasi menjadi lebih efisien dan up to date. Website juga merupakan media yang sangat cocok untuk mengenalkan kepada masyarakat secara luas tentang suatu potensi dan keunggulan suatu produk yang hendak dipasarkan (Hasugian, 2018).

Penggunaan website sebagai media promosi UMKM atap rumbia ini 
dimaksudkan untuk memperkenalkan suatu produk local Kelurahan Kalawa kepada khalayak secara luas. Setiap orang dengan kepentingan tertentu yang mencari informasi tentang Kelurahan Kalawa dengan cara mengunjungi website Kelurahan Kalawa akan disajikan sebuah iklan mengenai produk local atap rumbia. Subjek yang melihat informasi tersebut secara tidak langsung akan mendapatkan sebuah informasi tentang atap rumbia. Dengan diketahuinya informasi tersebut memberikan peluang untuk informasi mengenai atap rumbia ini semakin tersebar secara luas yang akan berdampak pada penjualan.

\section{KESIMPULAN}

Komunikasi pemasaran terpadu merupakan sebuah solusi alternative untuk memperkenalkan produk local kelurahan kalawa yaitu atap rumbia. Kegiatan komunikasi pemasaran terpadu atau yang dikenal dengan promosi ini dilakukan dengan menggunakan media yang berbeda-

\section{DAFTAR PUSTAKA}

Adnani. (2011). Teori Komunikasi: Sejarah, Metode, dan Terapan di dalam Media Massa. Jakarta: Kencana Prenanada Media Group. beda dan disesuaikan dengan kebutuhan serta situasi dan kondisi yang ada di Kelurahan Kalawa. Adapun media komunikasi pemasaran terpadu yang digunakan adalah penggunaan spanduk (banner), website, dan sosial media facebook. Dengan adanya kegiatan promosi ini diharapkan mampu memperkenalkan secara luas kerajinan atap rumbia yang berujung pada meningknya kondisi perekonomian masyarakat di Kelurahan kalawa.

\section{UCAPAN TERIMA KASIH}

Penulis mengucapkan terima kasih kepada pihak yang telah terlibat dan memfasilitasi baik secara moril maupun materil dalam penulisan naskah publikasi ini dalam hal ini adalah sebagai berikut.

- Universitas Palangka Raya.

- Pemerintah Kelurahan Kalawa.

- Masyarakat Kelurahan Kalawa.

- Kelompok 62 KKN-T Periode II Universitas Palangka Raya.

Akhter, S., Rizwan, M., Shujaat, S., \& Durrani, Z. (2014). The Impact of Retail Shoes Sales Promotional Activities on Ladies Purchase Intentions. Journal of Public Administration and Governance, 1660178. 
Chrismardani, Y. (2014). Komunikasi Pemasaran Terpadu : Implementasi untuk UMKM. Jurnal NeOBis , 176-189.

Duffett, R. G. (2015). Facebook Advertising's Influence on Intention-toPurchase and Purchase Amongst Millenials. Internet Research .

Ebeid, A. Y. (2014). Distribution Intensity, Advertising, Monetary Promotion, and Coustomer Based Brand Equality: An Applied Study in Egypt. International Journal of Marketing Studies , 113-122.

Fitriani, S. (2011). Promosi Kesehatan. Yogyakarta: Graha Ilmu.

Hasugian, P. S. (2018). Perancangan Website sebagai media Promosi dan Informasi. Journal of Informatic Pelita Nusantara, 82-86.

Hidayat, R., Utami, I. D., \& Romodhani. (2011). Pengembangan Strategi Komunikasi Pemasaran Industri Kecil Menengah (IKM). Journal of Strategic Communication , 205-221.

Iramsyah. (2018). Pengaruh Media Leaflet dan Spanduk Terhadap Pengetahuan dan Sikap Ibu Hamil Tentang Asi Eksklusif di Wilayah Kerja Puskesmas Blangpidie Kecamatan Blangpidie Kabupaten Aceh Barat Daya. Thesis. Medan: Universitas Sumatra Utara.
Khairani, Z., Soviyant, E., \& Aznuriyadi. (2018). Efektivitas Promosi Melalui Instagram pada UMKM Sektro Makanan dan Minuman di Kota Pekanbaru. Jurnal Benefita , 239-247.

Kotler, P., \& Amstrong, G. (2004). Dasar-dasar Pemasaran Jilid 2. (A. Sandoro, Trans.) Jakarta: Indeks.

Perwana, D., Rahmi, \& Aditya, S. (2017). Pemanfaatan Digital Marketing Bagi Usaha Mikro, Kecil dan Menengah (UMKM) di Kelurahan Malaka Sari, Duren Sawit. Jurnla Pemberdayaan Masyarakat Madani (JPMM) , 1-17.

Putri, W. G., \& Marlini. (2013). Rancangan Pembuatan Sarana Promosi di Taman Bacaan Masyarakat Suka Maju Sejahtera Padang. Jurnal Ilmu Informasi Perpustakaan dan Kearsipan , 450-460.

Rahayu, Y., Fitmawati, \& Herman. (2013). Ananlisis Keragaman Sagu (Metroxylon sagu Rottb.) pada Tiga Tipe Habitat di Pulau Pandang Kepulauan Meranti. Biosaintifika 5 , 16-24.

Samuel, H., \& Setiawan, Y. (2018). Promosi Melalui Sosial Media, Barand Awareness, Purchase Intention pada Produk Sepatu Olahraga. Jurnal Manajemen Pemasaran , 47-52.

Saputri, A., Amna, U., \& Navia, Z. I. (2018). Skring Fitokimia Buah Rumbia 
(Metroxylon sagu Rottb) : Studi

Pendahuluan Pengembangan Obat Herbal Anti Hipertensi. Prosiding Seminar

Nasional Pertanian dan Perikanan , 304309.
Schivinski, B., \& Dabrowski, D. (2015). The Impact of Brand Communication on Brand Equality Through Facebook. Journal of Research in Interactive Marketing , 31-53. 